\title{
Rearview
}

\section{In the USA, operators and regulators lurch towards $5 \mathrm{G}$}

\section{A regular column on the information industries}

\author{
Peter Curwen and Jason Whalley
}

Peter Curwen is Independent Scholar based at Leeds, UK. Jason Whalley is based at Newcastle Business School, Northumbria University, Newcastle upon Tyne, UK.

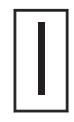

t is helpful to begin by shedding some light on the activities of T-Mobile, the mobile subsidiary of Germany's Deutsche Telekom (DT). Historically, T-Mobile was heavily focussed on Germany and the former Eastern Europe, but in recent years, it has become a major force in the USA, particularly since its merger with Sprint. In absolute terms, it claims to have more than 100 million subscribers in the USA, but DT only earns revenue from roughly 50 million, as it owns only $48.4 \%$ of its US subsidiary. This is comparable to Germany where it controls the entire network. Poland registers a distant third.

This matters because T-Mobile is now able to compete with AT\&T and Verizon on far more equal terms in the USA - to all intents and purposes, both AT\&T and Verizon are entirely US-centric in their mobile operations albeit with far fewer revenue-yielding subscribers. Until recently, T-Mobile in the USA played the role of disruptor via its "uncarrier" strategy with the emphasis on offers to subscribers that were more appealing than those of its rivals. However, the run-up to $5 \mathrm{G}$ has significantly altered the competitive scene, as described in what follows.
Since the beginning of 2017, the Federal Communications Commission (FCC) has set up a series of auctions for spectrum that could potentially be used extensively for 5G. These comprise the following:

- Auction 1001: $600 \mathrm{MHz}$ in April 2017 (reverse auction).

- Auction 1002: $600 \mathrm{MHz}$ in April 2017 (forward auction).

- Auction 101: $28 \mathrm{GHz}$ in January 2019.

- Auction 102: $24 \mathrm{GHz}$ in April 2019.

- Auction 103: Upper 37 GHz; 39 $\mathrm{GHz} ; 47 \mathrm{GHz}$ in January 2020.

- Auction 105: 3550-3700 MHz in August 2020.

- Auction 107: 3700-3980 MHz in January 2021

- Auction 108: $2.5 \mathrm{GHz}$ (decision pending).

- Auction 110: 3450-3550 MHz in November 2021.

It may be noted that these auctions have raised massive sums from operators, and that this has affected their ability to roll-out their networks; that Auctions 101, 102 and 103 involved so-called mmWave 
spectrum that is more suited for use in Internet of Things than for human-tomachine communication, and that the so-called mid-band spectrum on offer in more recent auctions is regarded as ideal for $5 \mathrm{G}$ - which is why Auction 107 raised an astonishing \$81bn.

There is currently some confusion about precisely what the different operators are providing because of the labels that they attach to their plans. The following breakdown, applicable as at end-2020, may accordingly be helpful.

- 5G: Used as a generic term but also still used by AT\&T for its 850 $\mathrm{MHz}$ network.

- 5G+: AT\&T's mmWave network.

- 5G Nationwide: Verizon's 850 $\mathrm{MHz}$ network utilising DSS.

- 5G Ultra Wideband: Verizon's mmWave network.

- Extended Range 5G: T-Mobile's $600 \mathrm{MHz}$ network.

- 5G Ultra Capacity: T-Mobile's new brand for the $2.5 \mathrm{GHz}$ spectrum network acquired from Sprint combined with its mmWave network.

Dynamic Spectrum Sharing (DSS) is a technology that allows an operator to switch between LTE (4G) and 5G depending upon the latter's availability. Where this occurs, the variant of $5 \mathrm{G}$ is known as Non-Standalone, whereas a network dedicated exclusively to $5 \mathrm{G}$ is known as Standalone. Although a few Standalone networks exist worldwide - including in the USA - they are for now extremely limited in scope.

Given the complexities of the above it may prove useful to note in summary that, as of June 2020, AT\&T had launched using the $850 \mathrm{MHz}$ and $39 \mathrm{GHz}$ mmWave bands (the latter on a very limited scale), Sprint using the 2.5 GHz band, Verizon using mmWave bands and T-Mobile using both $600 \mathrm{MHz}$ and mmWave bands. No other country in the world exhibits such complexity and the mixture of bands presented considerable difficulties for smartphone makers the only smartphone that supported both T-Mobile bands at the time was the Samsung Galaxy S20 UItra 5G as well as international roaming.

As noted previously, the chosen band affects both availability and downlink speed. These were analysed by OpenSignal in February 2020. It discovered that the average downlink was $723 \mathrm{Mbps}$ for Verizon, $243 \mathrm{Mbps}$ for T-Mobile mmWave, $183 \mathrm{Mbps}$ for Sprint, $59 \mathrm{Mbps}$ for AT\&T $850 \mathrm{MHz}$ and 47.5 Mbps for T-Mobile $600 \mathrm{MHz}$. In principle, availability should be inversely related to downlink speed and that turned out to be the case in general with the sub- $6 \mathrm{GHz}$ bands roughly five times as available as the mmWave bands. A subsequent report in June drew similar conclusions.

Although the situation is very fluid, and both downlink speeds and coverage vary considerably between operators, there can be no doubt that T-Mobile has chosen to be aggressively disruptive. Some useful comparisons between T-Mobile Uncarrier, AT\&T Unlimited Extra and Verizon Do More Unlimited in July were as follows:

- Cost per line/month: T-Mobile = $\$ 25 ; A T \& T=\$ 40 ;$ Verizon $=\$ 45$.

- 5G access: T-Mobile = included; AT\&T = included; Verizon = included for limited time then fee.

- Caller ID: T-Mobile = free; $A T \& T=$ $\$ 16$ monthly; Verizon = up to $\$ 8$ monthly.

In August 2020, T-Mobile claimed to have launched the world's first commercial nationwide Standalone $5 \mathrm{G}$ network using the $600 \mathrm{MHz}$ band. In October, it claimed that it had completed the first-ever Standalone data transfer using New Radio Carrier Aggregation in the $600 \mathrm{MHz}$ and 2.5 GHz bands and a LG Velvet $5 \mathrm{G}$ smartphone, in the process enabling its $5 \mathrm{G}$ network to increase both speed and reach simultaneously.

In September, AT\&T announced its intention to launch Standalone 5G before the year-end. However, it admitted that it had done little to expand its mmWave band services now lagging those of Verizon by a considerable margin - and that these were largely confined to enterprise use cases and venue-specific cases.

In October, Verizon activated a new "5G Nationwide" service - the FCC's definition of "nationwide" requiring that 200 million people were able to be served - that introduced DSS into its $5 \mathrm{G}$ network. However, it did not disclose which of its LTE bands were being shared. It added that it had been able to combine eight separate channels of mmWave spectrum so as to achieve a maximum downlink of 4 Gbps via what it branded its "ultrawideband" (UWB) service.

Nevertheless, Verizon confessed that the experience provided by LTE and $5 G$ would be similar. It would be providing $5 \mathrm{G}$ services primarily using its $850 \mathrm{MHz}$ band spectrum and hence the 4 Gbps that was technically accessible on the new iPhone 12 smartphone would rarely be available independent estimates suggested that coverage provided by its UWB was just $0.5 \%$ of the population.

The commonest view expressed by analysts was that even if AT\&T and Verizon obtained more spectrum than T-Mobile in the forthcoming C-band auction, they would still be playing catch-up for several years, especially as T-Mobile was the cheapest of the three for unlimited packages.

Also in December 2020, it was revealed by OpenSignal that the three incumbents were now providing roughly the same average $5 \mathrm{G}$ speeds in several major cities. This was somewhat surprising because for example, as noted above, Verizon had initially relied upon super-fast mmWave services whereas T-Mobile 
had initially relied upon the much slower $600 \mathrm{MHz}$ band. However, T-Mobile had speeded up as a result of the integration of Sprint's $2.5 \mathrm{GHz}$ spectrum.

It is significant that AT\&T and Verizon appeared to have divergent strategies. AT\&T, despite an acute cash shortage and substantial auction outlays to finance, offered a free iPhone 12 to new and existing subscribers while downplaying the future role of fixed-wireless connectivity. Verizon, in contrast, continued to attract FWA customers and to build up ARPU.

In March 2021, despite the above, AT\&T added a FWA service to its existing mobile provision. It noted that the substantial cost of rolling out its C-band network would be spread over several years, eliciting the response from $\mathrm{T}$-Mobile that it expected to complete its own 5G rollout before its rivals had even laid their hands on their C-band licences, and that it expected to use the synergies from its merger with Sprint to finance the roll-out.

In April, T-Mobile announced the launch of its "Home Internet" 5G service priced at $\$ 60$ a month for an average downlink of $100 \mathrm{Mbps}$. This was met with scepticism directed towards, for example, both the numbers of potential customers and the ability of T-Mobile to provide the ensuing demand for data transfers at the requisite speed. The same scepticism was directed at T-Mobile's "5G for all" offer that was based on the roll-out of its $600 \mathrm{MHz}$ network given that this provided little by way of speed enhancement and limited coverage.

Obfuscation is evidently the name of the game for incumbents. However, in May, the CEO of T-Mobile went on record with the claim that the game plan for $5 G$ was the same as for 4G, namely, to make money and increase its market share. This was underpinned by a strategy of persuading customers to upgrade from cheaper unlimited plans that involved throttling to the most expensive "Magenta Max" plan, introduced in February 2021. However, throttling would still take place once more than $50 \mathrm{~GB}$ of data was consumed monthly via a hot-spot.

For their parts, Verizon and AT\&T feel the need to be highly competitive. In June, Verizon more or less followed the T-Mobile lead by offering free $5 \mathrm{G}$ smartphones to customers who upgraded to its "Do More", "Play More" and "Get More" unlimited plans that provided access to its C-band and mmWave spectrum. Anyone switching from another operator would receive \$300. Meanwhile, AT\&T continued with its free iPhone 12 offer - see above that was costing it up to $\$ 800$ per customer in subsidy.

Also in June, Nokia announced that it would be deploying a 5G SA core for DISH on the Amazon Web Services public cloud which Nokia claimed would be the world's first roll-out of 5G SA in the public cloud - in this case supporting DISH's cloud-native Open RAN-based network. According to TeleGeography, the launch would commence in Las Vegas with coverage of $20 \%$ population pencilled in for June 2022

OpenSignal reported that the average mobile user accessed $5 G$ via a mmWave link less than one per cent of the time - specifically, T-Mobile $0.2 \%$, AT\&T $0.4 \%$ and Verizon $0.7 \%$. The view was frequently expressed that after the operators' recent massive expenditure on mid-band spectrum, this was only to be expected.

By autumn, competition also appeared to be ramping up with respect to FWA. In October 2021, T-Mobile announced a new Big Fee
Deal that gave Home Internet customers a $\$ 10$ reduction in their existing monthly fee of $\$ 60$ a month. Furthermore, there would be no annual contract and no data caps. This competition had the potential to hurt the cablecos but they, in turn, could also hurt the mobile operators by undercutting their prices via the established MVNO offerings using the Verizon network.

However, it could be argued that the key issue was whether T-Mobile intended to continue functioning as a disruptive force, and by end-October, this appeared to be the case, as it launched an offer whereby customers of AT\&T and Verizon who switched to T-Mobile would receive a payment equal to what they still owed on their smartphones up to a limit of $\$ 1,000$, a significantly cheaper family plan and much better $5 G$ coverage.

As all three incumbents now appear to be relying on a strategy that involves persuading customers to switch to their most expensive plans, the disruptive impact of T-Mobile has driven change within the sector while aligning their strategies. This heightens the importance of $5 \mathrm{G}$, encouraging the incumbents to invest in their networks, improving its coverage and performance. But at the same time, it is not clear whether AT\&T and Verizon will be able to regain some, let alone all, of the ground that they have lost to T-Mobile. The disruptive strategy of T-Mobile places AT\&T and Verizon in an uncomfortable position, needing to simultaneously invest large sums to roll out their $5 \mathrm{G}$ networks while competing to retain their subscribers. The dilemma for AT\&T and Verizon is whether it is worth it.

\section{Corresponding author}

Jason Whalley can be contacted at: jason.whalley@northumbria.ac.uk 